\title{
OPINIÃo de MULHERES DE UMA UNIDAde de SAÚde dA FAMília SOBRE A QUANTIDADE DE LEITE MATERNO PRODUZIDO ${ }^{1}$
}

\author{
Ana Luiza Vilela Borges ${ }^{2}$ \\ Sonia Tucunduva Philippi ${ }^{3}$
}

Borges ALV, Philippi ST. Opinião de mulheres de uma unidade de saúde da família sobre a quantidade de leite materno produzido. Rev Latino-am Enfermagem 2003 maio-junho; 11(3):287-92.

Trata-se de estudo com o objetivo de conhecer a opinião de mulheres sobre a quantidade de leite materno produzido, pois o leite insuficiente é uma das razões mais referidas por mulheres de diversas culturas, para a introdução de alimentos complementares na dieta de crianças, antes do quarto mês de vida. Foram entrevistadas 41 mulheres de uma unidade de saúde da família, na zona leste do Município de São Paulo, em seu próprio domicílio, em 1998 e 1999 . A maioria das mães $(82,9 \%)$ considerou estar produzindo uma quantidade suficiente de leite materno. Elas utilizaram, como critérios para a avaliação da quantidade de leite materno produzido, o volume das mamas, a drenagem espontânea de leite e o estado da criança após a mamada. Todas as mulheres introduziram leite artificial antes do quarto mês de idade, porém as que referiram leite materno insuficiente o fizeram mais precocemente $(p=0,0088)$.

DESCRITORES: aleitamento materno, leite humano, suplementação alimentar, enfermagem materno-infantil

\section{OPINION OF WOMEN FROM A FAMILY HEALTH UNIT ABOUT THE QUANTITY OF MOTHERMILK PRODUCED}

This is a study aimed at knowing the opinion of women about the quantity of mothermilk produced, since insufficient milk is one of the main reasons mentioned by women from different cultures when introducing complementary feeding in children's diet before the fourth month of life. The interviews were made at the homes of 41 women from a family health unit in the Eastern area of São Paulo City in 1998 and 1999. The majority of the mothers (82.9\%) considered they were producing a sufficient quantity of mothermilk. As evaluation criteria for the produced quantity of mothermilk, they used the size of the breasts, the spontaneous dropping of milk and the mood of the child after breastfeeding. All women introduced artificial milk before the fourth month, but those who mentioned insufficient milk did it earlier $(p=0.0088)$.

DESCRIPTORS: breastfeeding, human milk, supplementary feeding, maternal-child nursing

\section{OPINIÓN DE MUJERES DE UNA UNIDAD DE SALUD FAMILIAR SOBRE LA CANTIDAD DE LECHE MATERNA PRODUCIDA}

Este estudio tuvo como objetivo conocer la opinión de las mujeres en relación a la cantidad de leche materna que ellas produjeron durante la lactancia. La producción insuficiente de leche materna es una de las razones principales que las mujeres de diversas culturas argumentan para justificar la introducción de otros alimentos en la dieta de los niños antes del cuarto mes de vida. Entre 1998 y 1999, fueron entrevistadas, en su domicilio, 41 mujeres atendidas en la unidad de salud familiar de la zona éste del municipio de São Paulo. La mayoría de las madres (82,9\%) consideró que durante la amamentación produjeron una cantidad suficiente de leche materna. Los criterios, utilizados por ellas para calificar la cantidad de leche producida incluyeron, el volumen de los senos, la salida espontánea de leche y el estado de satisfacción del niño después de mamar. A pesar de que todas las mujeres comenzaron a dar leche artificial antes del cuarto mes de vida, aquellas que refirieron una producción insuficiente de leche materna, lo hicieron más precozmente $(p=0,0088)$.

DESCRIPTORES: lactancia materna, leche humana, alimentación suplementaria, enfermería maternoinfantil

\footnotetext{
${ }^{1}$ Parte da Dissertação de Mestrado de autoria de ALV Borges, apresentada ao Departamento de Nutrição da Faculdade de Saúde Pública da Universidade de São Paulo; ${ }^{2}$ Enfermeira, Doutoranda, e-mail: alvilela@usp.br; ${ }^{3}$ Professor Associado, e-mail: philippi@usp.br. Faculdade de Saúde Pública da Universidade de São Paulo
} 
INTRODUÇÃO

A primeira causa relacionada por mães de diversas culturas para a introdução de alimentos diferentes do leite humano, antes do quarto mês de vida do bebê, é a insuficiência de leite materno ${ }^{(1-4)}$.

No Brasil, vários estudos realizados com 0 objetivo de conhecer os determinantes do sucesso ou insucesso da amamentação também revelaram que as mulheres justificaram a introdução de complementos do leite materno por meio de falas muito comuns: "meu leite é pouco", "meu leite secou" " "a criança não quis o peito" 0 ${ }^{8)}$. Porém, os índices de hipogaláctia primária não ultrapassam $1,5 \%$ da população, e já foi comprovado que as nutrizes, do ponto de vista fisiológico, conseguem produzir quantidades adequadas de leite materno para assegurar um crescimento adequado para as crianças ${ }^{(9)}$.

Em estudo realizado na Suécia, com 51 pares mãe-filho, verificou-se que, apesar de todas as mulheres apresentarem condições favoráveis para um processo de lactação bem sucedido (alto nível de escolaridade, estímulo para amamentar exclusivamente até o sexto mês, chance de amamentar seu bebê na primeira hora pós-parto e acesso ao alojamento conjunto), $54,9 \%$ apresentaram a opinião de insuficiência de leite pelo menos uma vez ao longo da amamentação ${ }^{(3)}$.

Foram avaliadas mulheres de baixa renda no México e encontrou-se uma associação positiva entre ter percepção de insuficiência de leite em algum momento da lactação e introduzir alimentos complementares precocemente. Apenas $30 \%$ das mães que aleitaram exclusivamente até o quarto mês tiveram a percepção de insuficiência de leite, ao passo que, aproximadamente, $70 \%$ das mães que desmamaram seus filhos antes do quarto mês pós-parto, referiram, em algum momento, a percepção de que não tinham leite suficiente ${ }^{(4)}$.

A opinião materna de leite insuficiente parece ser, então, o reflexo de uma interpretação advinda do processo avaliativo que a mãe inicia logo no período pós-parto sobre a sua capacidade de aleitar. A mulher conduzirá a amamentação de acordo com os resultados vindos de sua avaliação, quando observa, dentre outros aspectos, 0 volume do leite materno produzido ${ }^{(10)}$. Caso a mulher conclua que a sua produção de leite materno está diminuída, ela poderá optar pela introdução de outros tipos de leite na alimentação da criança.

As conseqüências da introdução de alimentos complementares ou qualquer substituto do leite materno antes do quarto mês de vida da criança são graves para a saúde de crianças de países em desenvolvimento, aumentando o risco de morbidade e mortalidade ${ }^{(11)}$.

Este trabalho teve como objetivo conhecer a opinião de mulheres de uma unidade de saúde da família sobre a quantidade de leite materno por elas produzido no primeiro mês após o parto e a sua relação com a introdução de leites artificiais na dieta da criança.

\section{MATERIAL E MÉTODO}

A população em estudo foram todas as mulheres cadastradas ( $n=41)$ em uma unidade de saúde da família, da zona leste do Município de São Paulo, cujo parto ocorreu entre os dias $1^{\circ}$ e 31 de dezembro de 1998 e entre os dias $1^{\circ}$ e 31 de maio de 1999.

Primeiramente, foi determinado que as entrevistas seriam realizadas com todas as mulheres que tivessem seu parto a termo realizado no mês de dezembro de 1998 $(n=19)$. Como esse número pareceu não ser suficiente para que este estudo alcançasse os objetivos propostos, optou-se por incluir e entrevistar, também, as parturientes do mês de maio ( $n=25)$. Dentre essas 44 mulheres, três não puderam fazer parte do grupo pesquisado, pois houve uma doação de recém nascido para adoção ainda na maternidade, um natimorto e um óbito perinatal, sendo a amostra finalmente constituída por 41 mulheres.

Foram utilizados dois formulários estruturados para a entrevista individual com cada uma das participantes. O primeiro formulário foi aplicado por meio de uma entrevista no próprio domicílio da mulher, em torno do $30^{\circ}$ dia após o parto, para se conhecer sua opinião sobre a quantidade de leite materno produzido e os critérios utilizados para tal interpretação.

A partir daí, a cada 30 dias até o quarto mês pósparto, um segundo formulário estruturado foi aplicado com a finalidade de acompanhar a introdução de leites artificiais e alimentação complementar na dieta da criança.

Nenhuma mulher estava fazendo uso de contraceptivos hormonais orais ou injetáveis no momento da primeira entrevista, portanto foi descartada a possível influência que esse aspecto poderia exercer sobre a produção láctea naquele momento.

Para análise dos dados, utilizou-se o EPIINFO $6.0^{(12)}$. Os valores médios encontrados na variável 
introdução de leites artificiais foram comparados pelo teste de Mann-Whitney. O valor de p aceito foi menor que 0,05. Foi também realizada uma análise de conteúdo do discurso materno ${ }^{(13)}$

$\mathrm{Na}$ análise dos dados, as mulheres que relataram a produção de grande quantidade ou quantidade normal de leite materno foram classificadas como grupo leite suficiente ou LS. As mulheres que relataram a produção de pequena quantidade de leite materno foram classificadas como leite insuficiente ou LI.

Este estudo adotou procedimentos que garantiram a não-discriminação ou estigmatização das mulheres envolvidas na pesquisa, assim como o consentimento livre e esclarecido por escrito. Foram garantidos os aspectos referentes à privacidade, confidencialidade de dados, o anonimato, o respeito aos valores socioculturais, assim como a liberdade de retirar o consentimento a qualquer momento e deixar de participar do estudo.

\section{RESULTADOS}

A idade média das mulheres entrevistadas foi 26,19 anos (variação de 14 a 37 anos). A escolaridade revelou-se baixa, pois $58,5 \%(n=24)$ não chegaram a completar o primeiro grau, e apenas $12,2 \%(n=5)$ tinham o segundo grau completo. Nenhuma mulher referiu ser analfabeta ou ter concluído o terceiro grau. Aproximadamente $58 \%$ dessas mulheres não tinham renda própria nem contribuíam com a renda familiar, pois estavam desempregadas ou consideravam-se do lar.

A maioria das mulheres entrevistadas $(n=24)$ achou que produzia muito leite materno no primeiro mês pós-parto, totalizando $58,5 \%$, enquanto que $24,4 \%(n=10)$ acharam que produziam uma quantidade normal. Portanto, pode-se dizer que $82,9 \%$ das entrevistadas consideraram produzir uma quantidade suficiente de leite materno no primeiro mês pós-parto (LS), ao passo que apenas 7 $(17,1 \%)$ mulheres acharam que produziam uma pequena quantidade de leite (LI).

No tocante às explicações das mulheres sobre a suficiência ou insuficiência do seu leite, percebe-se que elas utilizaram os mesmos parâmetros para estabelecer a quantidade de leite produzido, como por exemplo:

a) observação da quantidade de leite materno drenado (Vaza muito. Derrama muito... Mama em um e o outro vaza... Nem vazou... Tinha que espremer...) b) o volume das mamas (Meu peito está bem maior... Se ela deixa de mamar uma vez, o peito já fica cheio, muito cheio... Quase não sinto meu peito cheio, carregado, pesado... Precisa um dia todo para encher o peito...)

c) o estado físico e psicológico da criança após a mamada

(O leite é bom. Ela dorme bastante. Eu acho que sustenta... A criança ficava chorando e só saía gota...)

As sete mulheres que referiram produzir pouco leite materno já haviam introduzido outros tipos de leite na dieta infantil, no primeiro mês pós-parto.

Quanto à introdução de leites artificiais na dieta da criança, a média foi de 52,4 dias ( $d p=42,2$ ), e a mediana, de 36 dias após o parto. Apenas uma mulher $(2,4 \%)$ aleitou exclusivamente até o quarto mês de vida da criança. Os leites administrados foram, em sua maioria, em pó, e os espessantes, utilizados largamente. As mães descreveram que o uso de outros leites era importante para que elas pudessem voltar logo ao trabalho, para sair em busca de um emprego, para realizar todo o trabalho doméstico e por causa do choro excessivo da criança. Foi observada diferença estatisticamente significativa em relação ao tempo médio de introdução de leites artificiais, segundo os grupos LI e LS ( $p=0,0088)$, conforme Tabela a seguir. As mães do grupo LI introduziram leites artificiais mais precocemente na dieta da criança e levaram menos da metade do tempo para interromper o aleitamento materno exclusivo do que as mães do grupo LS $(22,00 \mathrm{e}$ 58,65 dias em média, respectivamente).

Tabela 1 - Média, desvio-padrão (dp), valor mínimo (vmin) e máximo (vmax) e mediana da idade (em dias) de introdução de leites artificiais segundo grupos LI e LS

\begin{tabular}{c|ccccc}
\hline Grupo & Média & dp & Vmin & Vmax & Mediana \\
\hline $\mathrm{LI}^{1}$ & 22,00 & 38,1 & 2 & 108 & 7 \\
$\mathrm{LS}^{2}$ & 58,65 & 40,7 & 3 & 121 & 49 \\
\hline
\end{tabular}

${ }^{1}$ LI - Leite insuficiente

${ }^{2}$ LS - Leite suficiente

$\mathrm{p}=0,0088$ (Teste de Mann-Whitney)

Em relação à opinião das mulheres sobre a quantidade de leite materno consumido pela criança, $53,7 \%$ (n-22) das mães relataram que suas crianças consumiam uma quantidade normal de leite, $41,5 \%(n=17)$, que suas crianças consumiam uma grande quantidade de leite, e apenas $4,9 \%(n=2)$, uma pequena quantidade de leite.

As mães explicitaram que seus filhos consumiam 
uma grande quantidade de leite materno, principalmente porque o intervalo entre as mamadas era curto (Toda hora mama...) e porque os consideravam "gulosos" (Ele é guloso. Mama até engasgar e quer mais depois que engasga...).

As mães que concluíram que seus filhos consumiam uma quantidade normal de leite materno também utilizaram os mesmos critérios, inclusive o fato de que as crianças eram "gulosas" (É guloso! Toda hora quer... Toda hora quer. Muito voraz...É fominha; esganada. Vai com tudo! Puxa bastante... É exagerado para o seu tamanho... Desesperado! Guloso!).

Das 41 mães entrevistadas, duas (4,9\%)- do grupo LI- consideraram que seus filhos consumiam uma pequena quantidade de leite. As falas mostraram que essas mulheres usaram os mesmos indicadores "intervalo curto entre as mamadas" e "guloso" para definir o apetite das crianças. Então, na percepção materna, essas crianças queriam consumir uma maior quantidade de leite materno e, na verdade, consumiam uma pequena quantidade somente porque não havia oferta suficiente do mesmo ( $E$ ' muito guloso. Acaba de mamar e fica chupando a chupeta... Toda hora quer mamar...).

\section{DISCUSSÃO}

Os resultados revelaram que a maioria das mulheres $(82,9 \%)$ considerou estar produzindo uma quantidade de leite suficiente para satisfazer as necessidades do bebê no primeiro mês pós-parto, ao passo que apenas $17,1 \%$ revelaram estar produzindo leite insuficiente. Nesse aspecto, os resultados aqui descritos estão em desacordo com os resultados obtidos em outros estudos, onde $44 \%$ das mulheres tinham a opinião de que produziam uma quantidade insuficiente de leite materno no $8^{\circ}$ e $16^{\circ}$ dia pós-parto ${ }^{(14)}, 80 \%$ da amostra reportou baixa produção láctea ${ }^{(4)}$ e $54 \%$ de suecas com essa mesma opinião(3).

Esse resultado é importante no sentido de mostrar que, apesar de alguns estudos ${ }^{(5-8)}$ terem verificado a presença de opinião materna de baixa produção láctea, a maioria das mulheres desse grupo concluiu que tinha uma quantidade de leite suficiente para suprir as necessidades nutricionais de suas crianças, revelando uma auto-estima e confiança maiores em relação à amamentação.

Os indicadores utilizados para avaliação foram aqueles mesmos já descritos por outros autores ${ }^{(10,15)}$, como o volume das mamas, a drenagem espontânea de leite e o estado físico e psicológico da criança após a mamada. Os indicadores foram utilizados tanto por mulheres que consideraram ter leite suficiente (LS) quanto pelas que consideraram ter leite insuficiente (LI). As mulheres que concluíram que produziam muito leite pensavam assim porque o viram saindo em grande quantidade, vazando sem controle. Percebiam também as mamas cheias e volumosas e achavam que seus bebês estavam tranqüilos, felizes e sonolentos após a mamada. Assim, o sinal de produção láctea suficiente é intensamente perceptível para a mulher e está presente simultaneamente em seu próprio corpo (ao observar suas mamas) e em sua criança (ao observar seu estado após a mamada).

Nesse contexto, é importante salientar que as mães que se consideraram produzindo uma quantidade insuficiente de leite materno, tinham uma percepção real naquele momento, pois todas essas mães já haviam introduzido outros tipos de leite na dieta da criança, no momento da entrevista, e conseguiram estabelecer claramente, a relação mamadeira versus diminuição da produção láctea.

Não foi possível verificar se as mães tiveram uma produção láctea diminuída por já estarem utilizando leites artificiais na dieta da criança ou se, primeiramente, acharam que seu leite era insuficiente e só por isso introduziram leites artificiais, conforme descrito em outros estudos ${ }^{(3-}$ $4,14)$.

As mães do grupo LI interromperam mais precocemente o aleitamento exclusivo com a introdução de leite artificial na dieta da criança (aos 22 dias de idade em média) do que as mães do grupo LS (aos 58 dias de idade em média). A associação encontrada neste estudo entre a opinião materna de leite insuficiente e a introdução de leites artificiais precocemente $(p=0,0088)$ é compatível com outros trabalhos ${ }^{(3-4,14)}$, ratificando a opinião materna de leite insuficiente como um fator de risco importante para a interrupção do aleitamento materno exclusivo.

Contudo, a interrupção precoce do aleitamento exclusivo foi observada tanto no grupo LS quanto no grupo LI. Isso se deu pois alguns fatores influenciaram todas as mulheres, em maior ou menor grau, na decisão de continuar a amamentação, tais como a estrutura familiar, o trabalho, seja doméstico ou formal, e o corpo feminino, inclusive sua face reprodutiva, como o medo de uma nova gravidez. 
É preciso chamar a atenção para o fator trabalho. Mesmo que mais da metade das mulheres não tivessem qualquer fonte de renda, seja formal ou informal, e, portanto, aparente disponibilidade para amamentar, muitas relataram que as atividades domésticas e o cuidado com os outros filhos prejudicavam a condução da amamentação. As mulheres, geralmente, eram responsáveis por todo o trabalho doméstico e não contavam com a participação de nenhum outro membro familiar ou da comunidade para ajudá-las na execução dessas tarefas. Quanto às mulheres inseridas no mercado informal de trabalho, ficam claros os obstáculos ao sucesso da amamentação, visto que elas não tinham qualquer tipo de benefício social e retornaram precocemente ao trabalho, às vezes até antes do $30^{\circ}$ dia após o parto. Além disso, algumas mulheres formalmente empregadas relataram grande ansiedade em adaptar a criança a um outro tipo de alimento muito antes do término da licençamaternidade.

Assim, além da insuficiência do leite como causa importante de se interromper a amamentação, o trabalho feminino pode também estar influenciando isso negativamente, o que torna importante a formulação e aplicação de políticas públicas que protejam e estimulem a amamentação, pois outros resultados demonstraram que as mães mencionaram como causa prioritária para a interrupção do aleitamento materno o trabalho fora do $\operatorname{lar}^{(2)}$.

Outro fato que merece atenção são as descrições maternas em relação à quantidade de leite consumido pela criança. Os discursos das mães que consideraram seus filhos consumindo muito leite materno foram muito parecidos com as falas das mães que se consideraram produzindo uma quantidade normalde leite. Adjetivos como guloso, voraz e fominha foram usados tanto para qualificar crianças que consumiam uma quantidade normal de leite humano quanto para aquelas que consumiam uma grande quantidade de leite. Portanto, parece que, no imaginário materno, o apetite de um lactente é exagerado, e essa

\section{REFERÊNCIAS BIBLIOGRÁFICAS}

1. Carvalho M. Obstáculos ao aleitamento materno: fatos e mitos. J Pediatr 1985; 59:403-14.

2. Réa MF, Culkier R. Razões de desmame e de introdução de mamadeira: uma abordagem alternativa para seu estudo. Rev Saúde Pública 1988; 22(3):184-91.

3. Hillervik-Lindquist C, Hofvander $Y$, Sjölin S. Studies on perceived breast milk insufficiency. III. Consequences for breast milk consumption and growth. Acta Paediatr Scand 1991; 80:297-303. intensidade é esperada. A criança é geralmente vista como gulosa e, então, o leite precisa realmente ser um "super leite", em qualidade e quantidade, para dar conta de tal demanda.

Portanto, a equipe de saúde, quando assiste à mulher que amamenta, na atenção ao pré-natal, parto e puerpério, em ambiente hospitalar ou domiciliar, deve estar atenta aos critérios que as mulheres que amamentam utilizam para decidir se continuam ou interrompem a amamentação exclusiva. Informar as mulheres sobre os parâmetros adequados de produção láctea e o que se espera do comportamento de crianças pequenas, como 0 intervalo entre as mamadas e a presença do choro por inúmeras razões além da fome, pode contribuir para a postergação da introdução de alimentos diferentes do leite materno antes do quarto ao sexto mês de vida da criança e, conseqüentemente, aumentar o período de amamentação exclusiva.

\section{CONCLUSÕES}

As mulheres entrevistadas relataram, em sua maioria (34 mulheres ou 82,9\%), que produziam uma quantidade suficiente de leite materno para suprir as necessidades do bebê em torno do $30^{\circ}$ dia após o parto. Apenas sete mulheres $(17,1 \%)$ relataram que produziam uma quantidade insuficiente de leite humano.

Essas mulheres usaram como indicadores para a interpretação da quantidade de leite produzido o volume das mamas, a drenagem espontânea de leite e o estado da criança após a mamada.

A amamentação exclusiva foi interrompida precocemente pelas mulheres dos dois grupos estudados. Contudo, as mulheres que relataram uma produção láctea insuficiente, introduziram leites artificiais na dieta da criança antes das mulheres que relataram uma produção láctea suficiente.

4. Segura-Millan S, Dewey KG, Perez-Escamilla R. Factors associated with perceived insufficient milk in a low-income urban population in Mexico. J Nutr 1994; 124:202-12.

5. Souza LSF, Souza ELS, Barretto MRR, Ramos RTT, Macedo JJB, Serra CR, et al. Determinantes do êxito do aleitamento natural. J Pediatr 1991; 67:42-50.

6. Dávila EMM. Aleitamento Natural em um Centro Municipal de Saúde. Rev Nutrição PUCCAMP 1992; 5(2):157-70.

7. Costa MCO, Figueiredo EM, Silva SB. Aleitamento materno: causas de desmame e justificativa para amamentar. J Pediatr 1993; 63(3):176-8. 
8. Tabai KC, Carvalho JI, Salay E. Aleitamento materno e a prática de desmame em duas comunidades rurais de Piracicaba-SP. Rev Nutrição de Campinas 1998; 11(2):17383.

9. Akré J. Alimentação infantil: bases fisiológicas. Genebra: OMS; 1994.

10. Silva IA. Amamentar: uma questão de assumir riscos ou garantir benefícios. [tese]. São Paulo (SP): Escola de Enfermagem/USP; 1994.

11. Jelliffe DB, Jelliffe EFP. Human milk in the modern world. $2^{\text {nd }}$ ed. Oxford: Oxford University Press; 1978.

12. Dean AG, Dean JA, Coulombier D, Brendel KA, Smith DC, Burton $\mathrm{AH}$, et al. Epi Info, version 6: a word processing database and statistics program for epidemiology on microcomputers. Atlanta, Georgia, USA: Centers for Disease Control and Prevention; 1994.

13. Minayo MC. O desafio do conhecimento. São Paulo: Hucitec-Abrasco; 1992.

14. Perez-Escamilla R, Mejia LA, Dewey KG. Neonatal feeding patterns and reports of insufficient milk among low-income urban Mexican mothers. Ecol Food Nutr 1992; 27:91-102.

15. Hill PD. Some mothers who breastfeed perceive their milk supply as inadequate. Is it? Or, could that "insufficiency" have been avoided if the mother had had more help initially with breast feeding? Matern Child Nurs J 1991; 16:313-6. 